\title{
The Sustainability Professional
}

\author{
On the Record with Patricia Calkins \\ Global Vice President for Sustainability, Environment, Health, and Safety \\ Xerox
}

\begin{abstract}
It's possible to imagine that sustainability might be a bit of a hard sell at a company that makes printers, copiers, fax machines, toner, cartridges, paper, and ink, but the mantra at Xerox these days is "print responsibly." This company, which has its roots as a photographic paper manufacturer, clearly has learned to adapt with the times, thanks to the efforts of employees like Patricia Calkins, global vice president for sustainability, environment, health, and safety. That's a big title and a big responsibility: making sure that both employees and products are safe, and, increasingly, better for the planet. Sustainability: The Journal of Record interviewed Calkins about how Xerox manages to incorporate sustainability principles into its own operations and products, how it helps customers cut back on their own paper usage and still manages to stay in business, and whether she anticipates bringing on board a lot of new hires with degrees in sustainability.
\end{abstract}

What exactly do global vice presidents for sustainability, environment, health, and safety do?

Sustainability aspects are global. As corporations are trying to become global, it is really important that it is recognized that the role is global and that it is not just U.S.-based or just Europe-based. I have responsibility globally for setting leadership direction and getting the corporation aligned around that leadership and direction, and for providing the subject matter expertise to various parts of the company. I have to understand what is happening in the external world, all of the complex dynamics that go on, how they might interact with what we are doing inside the company, and then I get the appropriate people focused in on the things that they should be doing.

What sort of issues do you deal with beyond U.S. borders?

Europe has tended to be a little bit more in the forefront in terms of sensitivity in the area of sustainability, and they have got a whole lot more legislative activity going on. Some of the challenge is that, while we talk about Europe as one region, each member state is different. It is as if, in the United States, each individual state was acting very autonomously- which, of course, sometimes they do. But that creates a bit of a challenge. The developing parts of the world are really starting to move in this area also, and they have got their own challenges in trying to improve standard of living, which with it comes more consumption.

At Xerox specifically, we partner with Tokyo-based Fuji Xerox, with which we have a joint venture. (The joint venture between Fuji Photo Film and Xerox was established in 1962.) They have the marketing territory of Asia-Pacific, and we have the rest of the world. I need to make sure that we are consistent on our strategies and our standards and our practices. We have workshops twice a year to make sure that we continue to stay aligned on this and to learn from one another.

Do you have a staff, or are you a one-woman shop?

A lot of people, when they talk about sustainability, are talking about the environmental dimension. I am responsible for product safety. All of our products, no matter where they are being placed in the world, meet the product safety standards, such as those of the Underwriters Laboratory in the United States or the Canadian Standards Association in Canada or the CE marking in Europe, the GOST standard in Russia, the NOM requirements in Mexico. Basically, these standards make sure from the mechanical-electrical standpoint that our products are safe, and they also govern machine emissions and audible noise.

I also have responsibility for toxicology. We have got a group that works on two aspects, making sure that all the materials that we are using are safe, and then also administering health studies around exposure to toner, since toner is a critical element of operating our equipment. We have been conducting these studies for almost 30 years now, so we have high confidence that there are not any health issues associated with them.

I have workplace safety, so I'm responsible for all of our employees worldwide, whether they be working in our manufacturing facilities, in distribution, in sales, our service technicians. We also have a lot

\section{Close Up:}

Patricia Calkins

Years in current job: 5

Location of current job:

Rochester, NY

\section{Birthplace: Lincoln, MA}

Education: B.A. in biology from Merrimack College, M.S. in civil/environmental engineering from Tufts University, M.B.A. from the University of Rochester

Career Highlights: Was a chemist for AT\&T and a senior scientist at Abt Associates before joining Xerox

Career goals for 2010: To help drive Xerox to the next plateau, to have an influence on the integration of sustainability into the educational curriculum, and to help not only Xerox, but also all Xerox customers

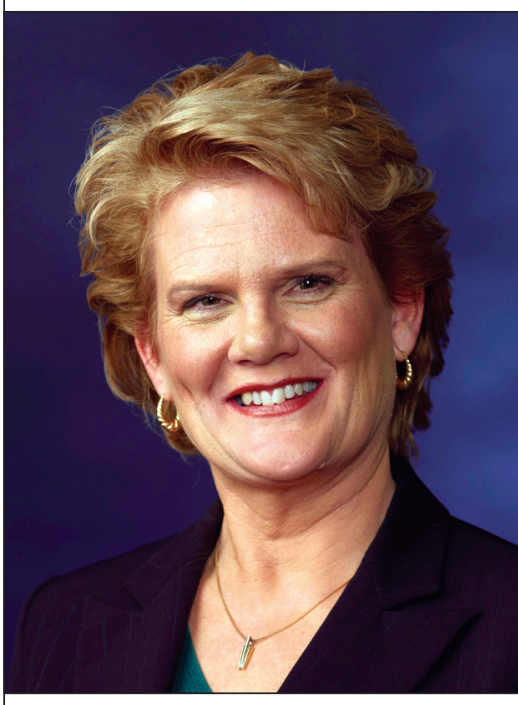

Patricia Calkins 
of Xerox employees who are actually located at our customers' sites managing their print needs. So I am responsible for employee safety for employees who are not only in our own environment, but also in a customer's working environment.

What we do is help customers optimize their print infrastructure by replacing multiple personal printers, standalone fax machines, and copiers with shared multifunction devices. That alone can significantly reduce their energy consumption by up to 50 percent.

Our medical organization I have responsibility for, not only the traditional, clinical-type medicine, but also the health and wellness programs that we are trying to drive proactively throughout our employee population and their families.

Then there's the traditional environmental compliance and regulatory requirements that I am responsible for. I have a team who manages environmental products and services. We work with our design teams on the design requirements we need to make sure that we continue to work into our products, and then we work that into services for our customers, to help our customers manage their environmental sustainability challenges.

We also have direct conduit from the field for customers to be able to call us. We have an 800 number and an e-mail. We also have extensive information that we provide externally on our website (www. xerox.com) so that when customers or anybody has questions, they can first go there, and then if they cannot get their questions answered, they can call into this group.

Then there's remediation-the cleaning up of past situations-as well as our corporate audit programs and real estate assessment. Before we buy a piece of property or if we are going to lease a piece of property, we make sure that it meets all of the Xerox environment, health, and safety requirements. And our standards go beyond regulatory requirements.

\section{Xerox at a Glance}

- Document management technology and services company that makes copiers, printers, fax machines, and associated software and supplies, including toner, paper, and ink

- Founded in 1906 in Rochester, NY, as the Haloid Company, which made and sold photographic paper; renamed Xerox Corporation in 1961

- In 1942, Chester Carlson, who invented xerography, produced the first xerographic image in his lab. Haloid acquired the license for Carlson's xerographic patents in 1947

Headquarters: Norwalk, CT

2008 revenue: $\$ 17.6$ billion

- Number of employees: 57,000 worldwide
Then I also have responsibility for business continuity for the corporation, so I am involved in things like pandemic preparedness planning. So, no, this is not a one-person effort.

Goodness, is there anything that Xerox does that you are not involved with?

I get to touch every part of the company, from one end of the spectrum to the other. We find that we end up also being almost like a systems integrator within the company. We will see things going on, and we will work on how to integrate this or that across the entire supply chain and leverage things so that we do them more effectively.

Our group is directly talking with customers all the time. It is different if we talk to customers and understand what their sustainability challenges are than if one of our marketing or sales people do, because we have some of the similar challenges. This enables us to translate it better into understanding how we can help them address their challenges.

What challenges do customers mention regarding sustainability?

Right now, there are three things. One is energy consumption, because everybody is concerned with climate change. We work to provide them with products that are more energy efficient. The majority of our products meet U.S. Environmental Protection Agency Energy Star requirements. Even as the bar at Energy Star continues to move, we stay out in front of that. We also help our customers right-size their print operations, because we have found that a typical organization has got way more print devices than they actually need. In fact, when we look at the utilization rate, the average utilization rate for a print device is 1 to 2 percent of the time, so the rest of the time they are sitting idle. But even if they are in sleep mode, they are still drawing power.

What we do is help customers optimize their print infrastructure by replacing multiple personal printers, standalone fax machines, and copiers with shared multifunction devices. That alone can significantly reduce their energy consumption by up to 50 percent. Then if you are replacing all those personal and single-function devices with a shared multifunction device that meets the newer Energy Star requirements, you can boost the energy savings up to almost 70 percent.

The second challenge customers face is paper. A lot of companies are looking at how to use less paper. We help them learn how to print responsibly, because they still do have print needs. For instance, they might set all of their devices with double-sided as the default mode, or scan documents to send as 
e-mail rather than printing them to send by postal mail. These are simple things that often folks have not thought about that they can do to help reduce their paper use. Another easy thing to do is to check that the paper they are using has been sustainably sourced. We started implementing requirements for our paper supply chain to restrict chemicals in the manufacturing process, to require that they have ISO 14001 certification, and to make sure that the fibers that go into manufacturing the paper have been sourced according to certified sustainable forestry practices.

Then the third challenge for customers is waste. They do not want to have to manage it, but they also do not want to throw things away. We have got a very extensive take-back program, not only for endof-life products, but for cartridges, and we remanufacture the cartridges and then recycle what cannot be remanufactured.

It's wonderful that Xerox is helping customers in this way, but how is persuading customers to use fewer Xerox products helping the company?

We are also introducing customers to new technologies and products that will help them, such as our solid ink printing technology. Rather than using powder toner, it uses a waxy material that is just like a crayon. You can literally take these ink sticks and draw with them. They come in the four different colors: yellow, red, blue, black. Because they are like crayon material in form, you can just take these ink sticks and plunk them right into the machine, and because of that, there are no cartridges. Because there are no cartridges and all the associated packaging, there is 90 percent less waste. There is very, very little waste associated with solid ink printing. Then, you also prevent all the environmental impact of not having to manufacture all of those cartridges and packaging, not having to transport them and store them.

We are developing, innovating new technologies to enable longer-lived parts for our laser products. Ideally, we are striving toward them lasting for the life of the machine so they will not have to be replaced. Just over the past few months, we introduced some newer technologies that have extended the lives of our photoreceptors and our fusers.

You appear in a video on Xerox's Thought Leadership page (www.xerox.com). What has the response been?

We launched that site about two years ago, and it was basically in response to our customers asking us to help them with how to their sustainability challenges, not so much from a, "Gee, what can Xerox do?" and a sales-y thing, but more in the area of thought leadership. We decided to launch

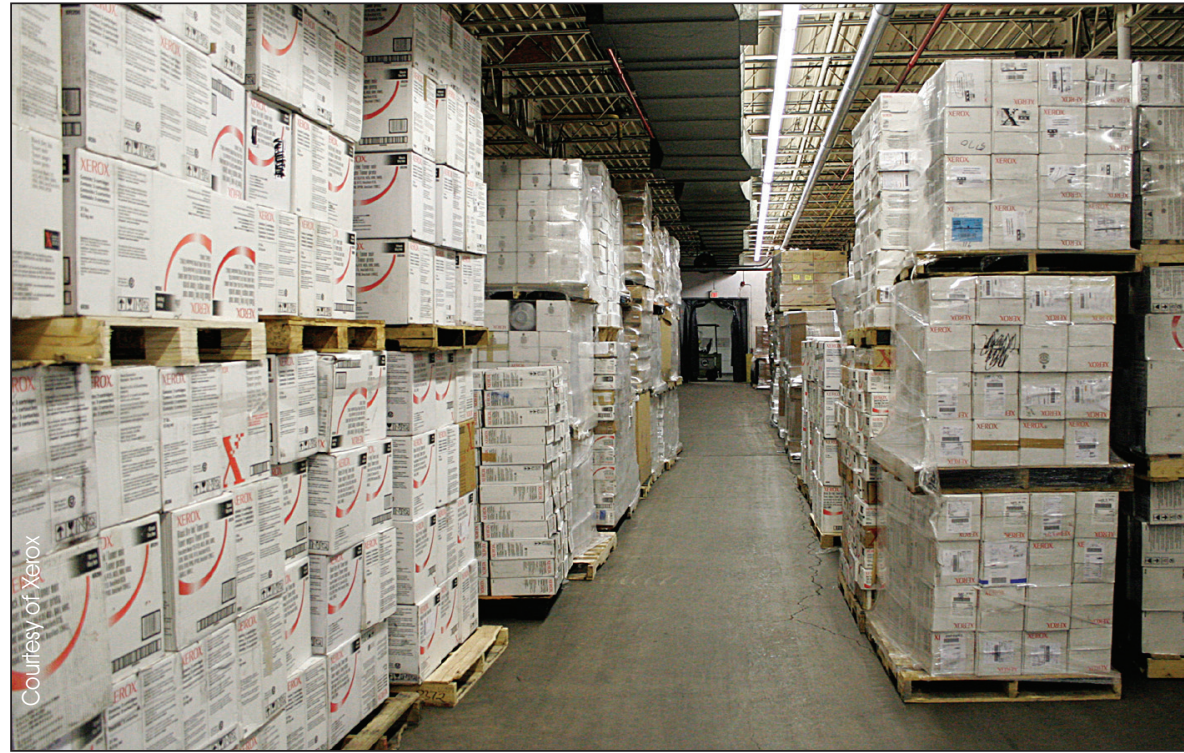

that thought leadership page, which was kind of interesting, because it signifies a change in my role, even, over the past five years, with what we are calling this awakening around sustainability. It used to be that when I was out speaking in external forums that the audience was made up of my peers at other companies, and the content would be very technical and on the forefront. Anyone new coming into that environment would not be able to understand what we were talking about. At some point, I noticed that there was a shift, that there were different people in the audience, and that we had an opportunity to help bring them along and build their knowledge and help these people get started implementing these ideas at their own companies. We launched that thought leadership site as a resource for customers, partners, and anyone interested in making their company more sustainable.

We also hold thought leadership forums, in various geographies, where we invite local businesses, government, academia, and whoever wants to participate for lunch or breakfast, and facilitate a dialogue on what sustainability is, why should we care, why it is not going away-even with these tough economic times-how to get started, or, if you are already started and you are looking for new ideas or how to reinvigorate your program or really take the next step function forward. Those forums are always fun.

Are you seeing more potential recruits who have sustainability degrees?

I love working with universities. We also do thought leadership things for higher education. I did one in Massachusetts last spring that was hosted by Stonehill College in Easton, and they invited in a bunch of other colleges and universities in the area to talk about sustainability, and there were several speakers,
We have got a very extensive take-back program, not only for end-of-life products, but for cartridges.

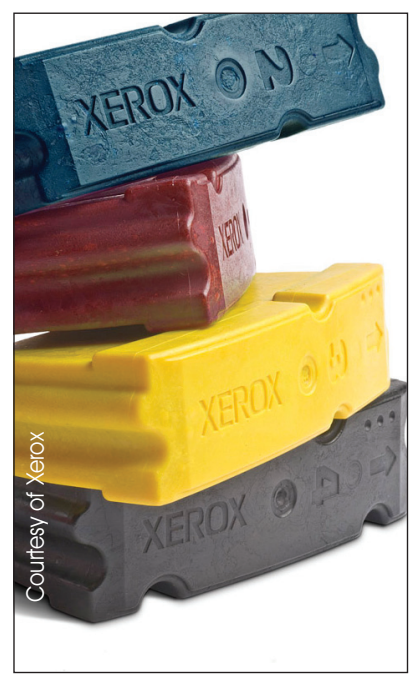


The notion of sustainability needs to be integrated into the current traditional curriculum, because I think that if you have it separate, it continues to be seen as something separate as opposed to something integral.

myself included. Tony Cortese, who is the head of Second Nature (and on the editorial board of Sustainability: The Journal of Record) was there. It was a great discussion, and the best discussion happened after all the presentations were complete and we were talking about how to work together more as a network and perhaps have workshops around how universities can leverage each other's knowledge.

The idea of having a specific sustainability major, I am not quite sure I know what that is. The notion of sustainability needs to be integrated into the current traditional curriculum, because I think that if you have it separate, it continues to be seen as something separate as opposed to something integral. I think it is easier for universities to just say, "Okay, well I have a sustainability major," rather than figure out, "How do I get this as a core, fundamental aspect of all my curriculum?" That's actually feedback that I've received from a couple universities.

The whole education side of this is so important to me, because it is the only way that we are actually going to get this integrated into people's thinking.
You are still going to need the people who are the deep-dive experts, because there are so many complexities, particularly around the science, and the different stakeholders and trying to tease out what is perception versus what is science. You are always going to need people who have a real strong technical aptitude and systems thinking to be able to help pull things together in a meaningful way and help make decisions that are the right decisions. But you still need to have your finance people, your operations people, your marketing people, your product development people all having this as part of their fabric as they are doing their job in their portion of the organization.

Some people think it will take a generation before sustainability is really integrated into our thinking and our habits.

That is the frustrating thing. We need to have it happen overnight, we want to have it happen overnight, but we have got to have the discipline and patience and fortitude to continue to forge forward and knowing that it is going to take time. 